\title{
The Choice of Appropriate Scenario in Order to Reduce the Effect of Thermal Pollution at the Damietta Branch Caused by Cooling Water Discharged from Kafr-Al-Batek Power Station
}

\author{
Saadeldin K. Mostafa, Mohamed K. Mostafa, Jason T. Kirby \\ Department of Civil, Construction, and Environmental Engineering at University of Alabama at Birmingham, \\ Birmingham, AL, USA \\ Email: $\underline{\text { mkhaled@uab.edu }}$
}

Received 6 June 2015; accepted 25 August 2015; published 28 August 2015

Copyright (C) 2015 by authors and Scientific Research Publishing Inc.

This work is licensed under the Creative Commons Attribution International License (CC BY). http://creativecommons.org/licenses/by/4.0/ (c) $\underset{\mathrm{EY}}{\mathrm{P}}$ Open Access

\section{Abstract}

The main purpose of this research effort was to investigate and reduce the volume of thermal polluted cooling water from returning to the Kafr-Al-Batek power station. Traditional cooling systems, such as cooling towers or ponds can be very challenging with regards to implementation in developing countries; mainly due to the lack of financial capacity. This research focused on lowcost simulation solutions that could improve thermal outcomes. Comparisons were performed between three different scenarios to decrease the elevated temperature of the discharged water $\left(43^{\circ} \mathrm{C}\right)$ released by the Kafr-Al-Batek power station on the Damietta branch. The different scenarios were simulated by using Star CCM+ software. The base scenario examined the discharge angle of an existing outlet. The second scenario examined a new outlet downstream from the existing outlet. The third scenario increased the width of the existing outlet in order to reduce flow velocity. A comparative analysis is provided between the aforementioned solutions to identify the most suitable and cost-effective alternative. Simulation results show that changing the discharge angle from $90^{\circ}$ to $135^{\circ}$ is the most effective solution. Applying this solution has the potential to decrease the water temperature at the inlet by 7 degrees Celsius (from $32^{\circ} \mathrm{C}$ to $25^{\circ} \mathrm{C}$ ).

\section{Keywords}

Thermal Pollution, Short-Circuiting, CFD Software, Kafr-Al-Batek Power Station, Damietta Branch, Egypt 


\section{Introduction}

Thermal pollution is the act of changing the surface water's temperature which may cause a degradation of water quality [1]. A common cause of thermal pollution is the use of surface water as a coolant by industrial manufacturers and power plants [2]. Frequently, power plants discharge cooling waters at nearly $+10^{\circ} \mathrm{C}$ higher than the coolant receiving waters [3]. Thermal pollution may decrease the dissolved oxygen and may affects ecosystem composition. Significant increases in water temperature can adversely affects the normal activities of aquatic organisms including reproduction [1] [2]. Elevated temperature of the discharged water, as well as the water contaminants, can further negatively affect water quality and all marine life [3] [4]. Globally, researchers have conducted numerous studies to address the topic of thermal pollution. In 2003, Nordell noted that the thermal pollution could even contribute to global warming. The results also showed that the combustion of fossil fuels and nuclear power were the main source of thermal pollution [5]. Walkuska and Agnieszka [6] addressed the effect of heated water on aquatic ecosystem fauna with results indicating that the increase in water temperature in a reservoir led to adverse changes in aquatic ecosystem function and affected indigenous animals. The results also showed that even small changes in water temperature might exacerbate the activity of infectious disease and parasitic agents that could further damage native fauna populations. These studies and other have concluded that the increasing water temperature could lead to more frequent infections in animals by affecting the animal's immune system and by influencing pathogenicity.

One of the facilities that face this problem is the Kafr-Al-Batek power station located along the Damietta branch in Egypt. This station has a net design capacity of 1200 MW, making it one of the largest power stations in Egypt. Daily, the facility discharges nearly $3.20 \times 10^{6} \mathrm{~m}^{3}$ of cooling water to the adjacent water body. Elevated temperature can reach $43^{\circ} \mathrm{C}\left(\sim 18^{\circ} \mathrm{C}\right.$ higher than the normal river temperature). In violation of Egyptian law, outcomes of the thermal pollution can include fish kills along the Damietta branch [4]. An average temperature of $32^{\circ} \mathrm{C}$ was observed at the intake of the Kafr-Al-Batek power station during fish kill events. This phenomenon results from the insufficient hydraulic separation between the cooling system's inlet and outlet structures (see Figure 1). Furthermore, because the water velocity at the outlet $(2.0 \mathrm{~m} / \mathrm{sec})$ is much higher than the water velocity upstream of the outlet $(0.37 \mathrm{~m} / \mathrm{sec})$, the discharged water can flow nearly perpendicularly to the river where it is obstructed by an erosion protection wall (see Figure 1). Coupled with the intake velocity (3.0 $\mathrm{m} / \mathrm{s}$ ), the thermal flux is dissipated upstream and can adversely influence the cooling system [4].

Short-circuiting is the process of returning the thermally charged cooling water to the power station. This problem mainly occurs when the river velocity is relatively low when compared to the withdrawing velocity at the inlet of the power station [4]. Common techniques in the United States to prevent cooling water recirculation include cooling towers or ponds; though these devices are not used in developing countries such as Egypt due to a lack of financial capital. This research aims to reduce the effects of thermal pollution by hydraulically separating previously heated water (discharge water) from returning to the power station.

\section{Materials and Methods}

\subsection{Study Area}

The research was carried out in the Damietta branch of the Nile River which measure approximately $245 \mathrm{~km}$ (152.2 miles). The Damietta branch receives thermally polluted cooling water from Kafr-Al-Batek power station. The study area included about 1712 m (1.064 miles) of the Damietta branch, as shown in Figure 2.

Sample collection began in December 2012 and ended in October 2013 and involved taking water samples from 20 sites every 30 days along the Damietta branch; three sites downstream the outlet of the station, three sites at the outlet of the station, six sites upstream the outlet of the station, three sites at the inlet of the station, three sites upstream the inlet of the station, and two sites inside the inlet and the outlet of the station. Approximately 220 samples were collected and analyzed according to the standard methods for wastewater analysis [7]. Water samples were collected in polyethylene containers (2-liter capacity) at a depth of $0.3 \mathrm{~m}$ (1.0 feet) under the water surface [8] [9]. At least three samples along the river width were collected, one from the middle section of the river and two $30 \mathrm{~m}$ from the river banks [4]. A WTW multi 340i meter enabled measurement of temperature, $\mathrm{pH}$, and dissolved oxygen (DO) in the field. The flow velocity was measured by using the water flow probe shown in Figure 3. A weighted wire allowed measurement of the depth of the outlet, as well as the depth of the river at any specific point. A tape measure was used to measure the width of the outlet. 


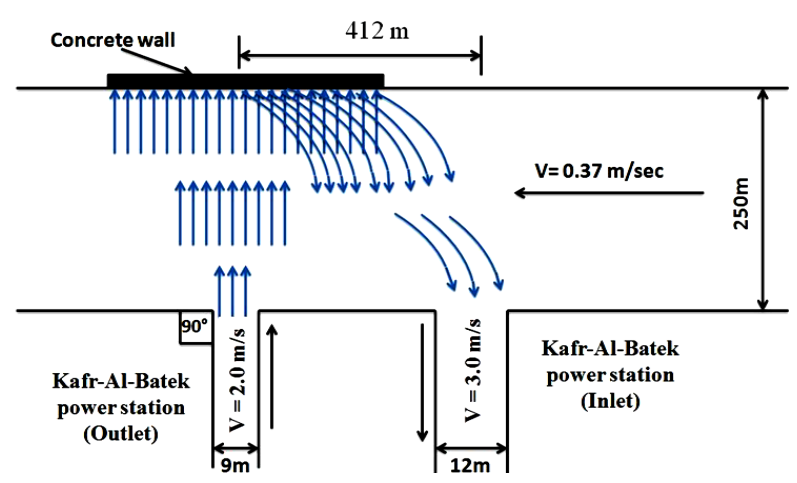

Figure 1. The water flow pathway at the Kafr Al-Batek power station.

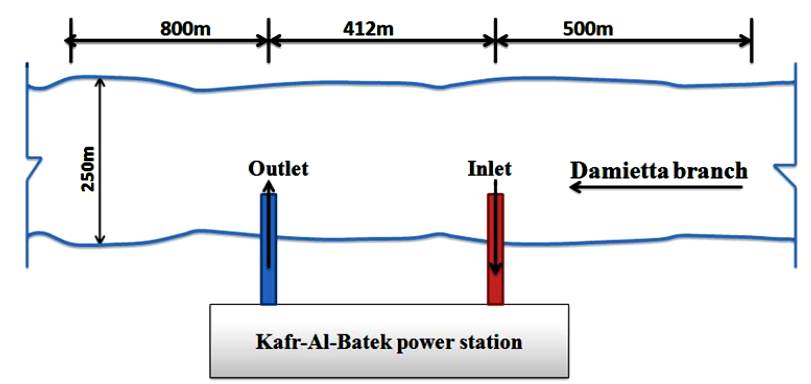

Figure 2. Study area at the Damietta branch.

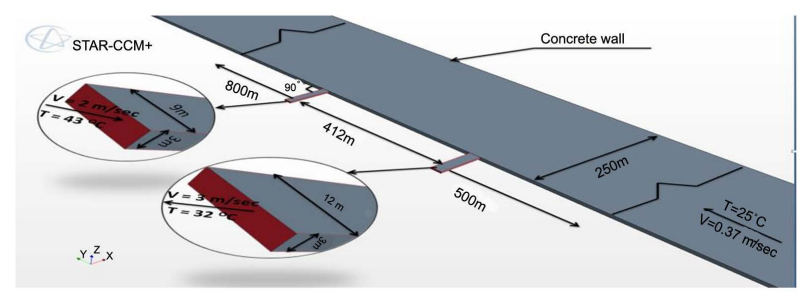

Figure 3. Simulation geometry and boundary conditions.

\subsection{Simulation Details}

Star CCM+ was used to model and simulate the scenarios in this research effort. Star CCM+ provides complete mesh flexibility [10]. Solving flow problems with unstructured meshes that can be generated about complex geometries with relative ease [10]. The governing equations of fluid flow and heat transfer adapted for Star CCM+ used in the present investigation are given as basic conservation laws of physics according to the following assumptions: steady three dimensional flows and gravity included in the negative z-direction [11]. To prove the efficiency and validity of the modeling, regression analysis for the actual and predicted values was performed within Microsoft Excel, and the correlation coefficients were obtained for use in identifying the nature of correlations between the actual and predicted values.

The model geometry and boundary conditions are shown in Figure 3. The river width and depth are taken as $250 \mathrm{~m}$ and $4 \mathrm{~m}$, respectively. The Damietta branch has an average velocity of $0.37 \mathrm{~m} / \mathrm{s}$ for much of its length and the slope is taken as $6.5 \mathrm{~cm} / \mathrm{km}$. The study area included $1712 \mathrm{~m}$ (1.064 miles). In order to ensure arobust simulation result, a $500 \mathrm{~m}$ section has been assigned as the entrance length along the main river and the inlet of the Kafr-Al-Batek power station. Furthermore, a distance of $800 \mathrm{~m}$ was assigned after the outlet of the station; this longer distance provides better insight regarding the temperature distribution after discharge occurs. The inlet channel of the station was assumed to be rectangular channel with a withdrawing velocity of $3 \mathrm{~m} / \mathrm{s}$ and depth of flow is $3 \mathrm{~m}$. The channel width is taken as $12 \mathrm{~m}$. The outlet channel of the station has a width of $9 \mathrm{~m}$, water 
depth of $3 \mathrm{~m}$ and the cooling water is discharging at a velocity of $2 \mathrm{~m} / \mathrm{sec}$. The water temperature upstream the inlet of the station was found to be $25^{\circ} \mathrm{C}$, while the temperature inside the inlet and the outlet of the station was found to be $32^{\circ} \mathrm{C}$ and $43^{\circ} \mathrm{C}$, respectively (see Figure 3). The model also includes a pre-existing concrete wall that is constructed on the adjacent side of the river to prevent erosion/flooding.

Geometries in this research are meshed using a prism layer. A prism layer is a layer of cells extending from the surface of geometry (see Figure 4). All prism layers have a stretching ratio (SR) [12]. This means that the cells are stretched in wall-normal direction using the stretching ratio. For instance, a stretching ratio of 1.2 means that a layer of cells in the prism layer has a height 1.2 as much as the previous layer [12]. Assumptions regarding the mesh properties included the base size is $5.0 \mathrm{~m}$ (approximately $10 \%$ of the entire diameter), the number of prism layers is 10, prism layer stretching 1.2, prism layer thickness (Relative size) is 10\%, the surface size (relative minimum size) is $5 \%$, and surface size (relative target size) is $25 \%$.

\subsection{Mass, Momentum, and Energy Equations Used by Star-CCM+ Software}

Star CCM+ was used to model and simulate the different proposed scenarios in this study. Star CCM+ provides complete mesh flexibility [10]. Solving flow problems with unstructured meshes that can be generated about complex geometries with relative ease [10]. The governing equations of fluid flow and heat transfer adapted for Star CCM+ used in the present investigation are given; using basic conservation laws of physics according to the following assumptions: steady three dimensional flows and gravity included in the negative z-direction [11].

For the fluid element, the rate of increase of mass in fluid element equals the net rate of flow of mass into element. The mass balance can be expressed by the following equation [11]:

$$
\frac{\partial \rho}{\partial t}+\frac{\partial(\rho u)}{\partial x}+\frac{\partial(\rho v)}{\partial y}+\frac{\partial(\rho w)}{\partial z}=0
$$

or written in vector notation:

$$
\operatorname{div}(\rho u)+\frac{\partial \rho}{\partial t}=0
$$

Equation (4.2) is the unsteady, three-dimensional mass conservation or continuity equation at a point in a compressible fluid. The first term on the left side called "the convective term", and describes the net flow of mass leaving the elements across its boundaries [11]. The second term is the rate of change in time of the density (mass per unit volume). For an incompressible fluid, the density $(\rho)$ is constant and Equation (4.2) becomes [11]:

$$
\operatorname{div}(u)=0
$$

or in longhand notation:

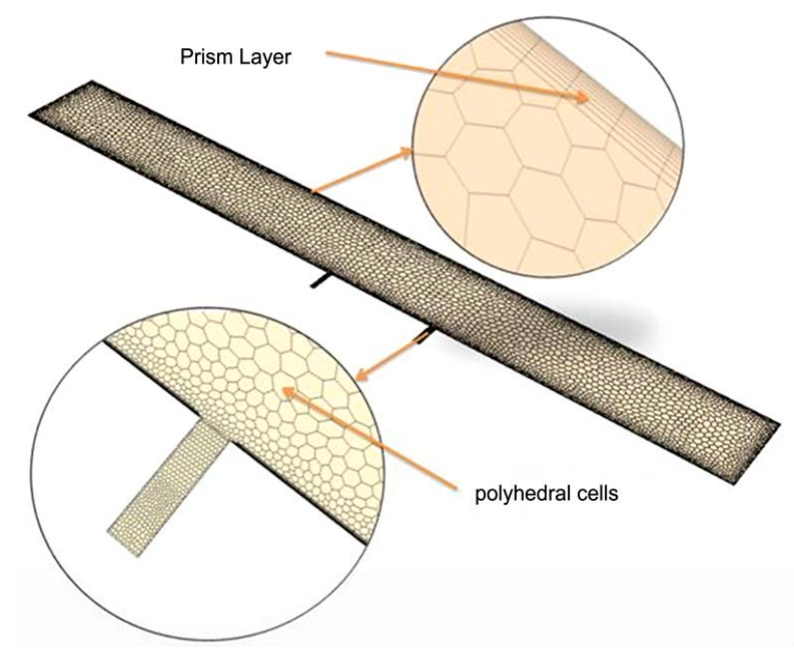

Figure 4. The prism layer and polyhedral cells (from Star CCM+ program). 


$$
\frac{\partial u}{\partial x}+\frac{\partial v}{\partial y}+\frac{\partial w}{\partial z}=0
$$

For the momentum equation, Newton's second law states that the rate of change of momentum of a fluid particle equals the sum of the forces on the particle. The rates of increase of $x, y$ and $z$ momentum per unit volume of a fluid particle are given by:

$$
\begin{aligned}
& \rho \frac{D u}{D t}=\frac{\partial\left(-p+\tau_{x x}\right)}{\partial x}+\frac{\partial \tau_{y x}}{\partial y}+\frac{\partial \tau_{z x}}{\partial z}+S_{M x} \\
& \rho \frac{D v}{D t}=\frac{\partial \tau_{x y}}{\partial x}+\frac{\partial\left(-p+\tau_{y y}\right)}{\partial y}+\frac{\partial \tau_{z y}}{\partial z}+S_{M y} \\
& \rho \frac{D w}{D t}=\frac{\partial \tau_{x z}}{\partial x}+\frac{\partial \tau_{y z}}{\partial y}+\frac{\partial\left(-p+\tau_{z z}\right)}{\partial z}+S_{M z}
\end{aligned}
$$

Equation (4.8) represents a transport equation that can be used to describe how a scalar, $\phi$, changes in a closed physical system as a consequence of diffusion and convection [13].

$$
\frac{\mathrm{d}}{\mathrm{d} t} \int_{V} \rho x \phi \mathrm{d} V+\oint_{A}\left[\rho \phi\left(v-v_{g}\right)\right] \cdot \mathrm{d} a=\oint_{A} \Gamma \nabla \phi \cdot \mathrm{d} a+\int_{V} S_{\phi} \mathrm{d} V
$$

where $\phi=$ the transported scalar, e.g. temperature, energy or mass.

$V=$ the cell volume $\left(\mathrm{m}^{3}\right)$.

$A=$ the cell surface-area $\left(\mathrm{m}^{2}\right)$.

$\rho=$ the density $\left(\mathrm{m}^{3} / \mathrm{kg}\right)$.

$x=$ the porosity (dimensionless).

$A=$ the cell area $\left(\mathrm{m}^{2}\right)$.

$\Gamma=$ the diffusion coefficient (dimensionless).

$a=$ the face area vector $\left(\mathrm{m}^{2}\right)$.

$v=$ the velocity $(\mathrm{m} / \mathrm{s})$.

$v_{g}=$ the grid-velocity $(\mathrm{m} / \mathrm{s})$.

$S_{\phi}=$ a source term for the scalar $(\mathrm{N})$.

The energy equation can be obtained from Equation (4.8) to describe the transport of energy $(E)$ in a solid:

$$
\frac{\mathrm{d}}{\mathrm{d} t} \int_{V} \rho C_{p} T \mathrm{~d} V+\oint_{A}\left[\rho C_{p} T v_{s}\right] \cdot \mathrm{d} a=-\oint_{A} q^{\prime \prime} \cdot \mathrm{d} a+\int_{V} S_{u} \mathrm{~d} V
$$

where $C_{P}=$ the material's specific heat capacity $(\mathrm{J} / \mathrm{kg} \cdot \mathrm{K})$.

$q^{\prime \prime}=$ the heat flux vector (W).

$s_{u}=$ energy source term whose definition depends on the physical models $(\mathrm{N})$.

$v_{s}=$ solid convective velocity which can be used to model rotation of a pure body $(\mathrm{m} / \mathrm{s})$.

The energy equation for a fluid is represented by Equation (4.10). The commercial software STAR-CCM+ used in this project employs finite volume methods (FVM) to solve Equations (4.8) and (4.10) in order to determine the behavior of the physical system.

$$
\frac{\mathrm{d}}{\mathrm{d} t} \int_{V} \rho E \mathrm{~d} V+\oint_{A}\left[\rho H\left(v-v_{g}\right)+v_{g} P\right] \cdot \mathrm{d} a=-\oint_{A} q^{\prime \prime} \cdot \mathrm{d} a+\oint T \cdot v \mathrm{~d} a+\int_{V} f \cdot v \mathrm{~d} V+\int_{V} S_{u} \mathrm{~d} V
$$

where $E$ = the total energy $H-P / \rho(\mathrm{J})$.

$H=$ the total enthalpy $\left(C_{p} T+|v|^{2} / 2\right)(\mathrm{J})$.

$T=$ the viscous stress tensor which consists of a laminar and a turbulent part $\left(\mathrm{N} / \mathrm{m}^{2}\right)$.

$f=$ the body force vector $(\mathrm{N})$.

$q^{\prime \prime}=$ the heat flux vector $(\mathrm{W})$.

$N=$ the velocity vector $(\mathrm{m} / \mathrm{s})$.

$v_{g}=$ the grid velocity vector $(\mathrm{m} / \mathrm{s})$. 
$u_{s}=$ contributes more energy source terms $(\mathrm{N})$.

This research aims to reduce the effect of the thermal pollution by preventing the cooling water from being short circuited by the Kafr Al-Batek power station. The different scenarios, simulated by using Star CCM+ software, are: 1) a scenario developed to optimize the width of the existing outlet, 2) a scenario developed to close the existing water outlet and construct/optimize a new outlet downstream, and 3) a scenario developed to optimize the discharge angle of the existing outlet. Finally, a comparison was conducted between the aforementioned scenarios to find the most suitable and cost effective solution to be implemented.

\section{Results and Discussion}

\subsection{Comparison between Actual and Predicted Values}

Figure 5 depicts the measured temperature distribution upstream and downstream of the Kafr-Al-Batek power station. At the intake of the Kafr-Al-Batek power station, an average temperature of $32^{\circ} \mathrm{C}$ was observed, which resulted from the inadequate spatial distance between the inlet and the outlet.

The accuracy of the Star CCM+ modeling was verified by comparing between the actual data and those achieved by using the model (Table 1). The actual data was extracted from Figure 5.

The correlation coefficient, $r$, between the actual and predicted values was found to be 0.998 , as well as the coefficient of determination, $R^{2}$, was found to be 0.9979 , as shown in Figure 6. Consequently, there is a significant Correlation between the Modeling data and the actual data collected.

\subsection{Simulation Results}

First, the Computational fluid dynamics (CFD) analysis was performed using Star CCM+ to simulate the current situation to allow for the baseline assessment of the real-life problem. In the current situation, the outlet is located $412 \mathrm{~m}$ downstream the inlet of the station and the discharge angle is perpendicular to the river flow. Figure 7 shows that the annual water temperature at the inlet of the station $\left(32.2^{\circ} \mathrm{C}\right)$ is 7.20 degrees higher than the

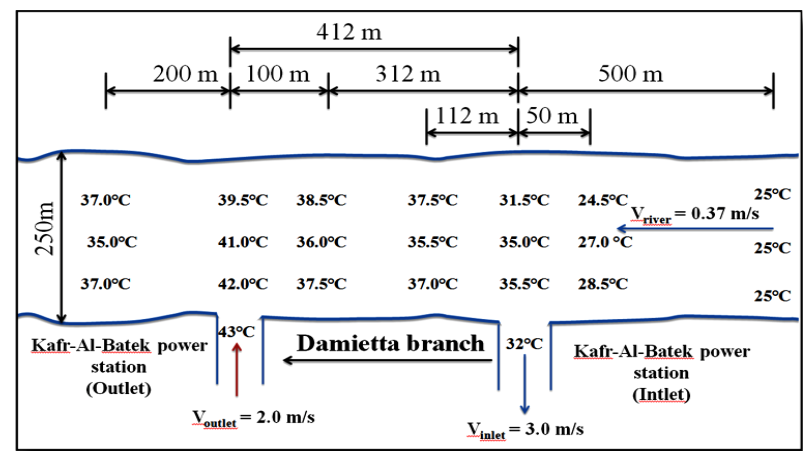

Figure 5. Average annual temperature for water samples collected along the Damietta branch.

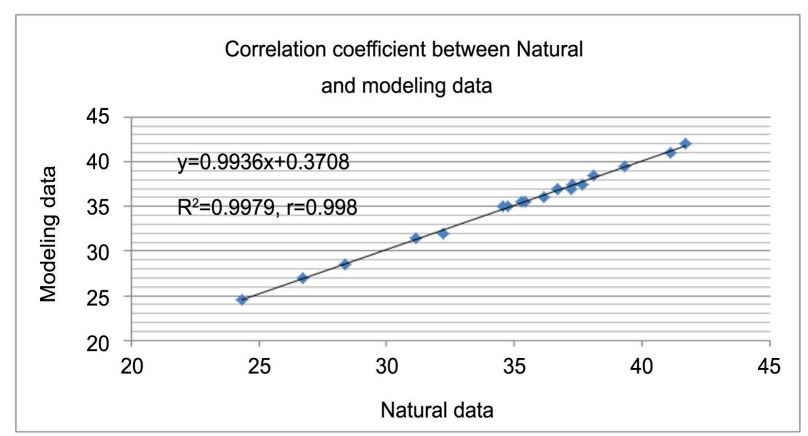

Figure 6. Statistical relationship between natural and modeling data. 
Table 1. Actual and predicted water temperature within the study area.

\begin{tabular}{|c|c|c|c|}
\hline Location & Predicted, temperature, $\left({ }^{\circ} \mathrm{C}\right)$ & Actual, temperature, $\left({ }^{\circ} \mathrm{C}\right)$ & $\Delta \mathrm{T}\left({ }^{\circ} \mathrm{C}\right)$ \\
\hline $200 \mathrm{~m}$ downstream the outlet of the station (LB) & 37.22 & 37.0 & +0.22 \\
\hline $200 \mathrm{~m}$ downstream the outlet of the station (M) & 34.75 & 35.0 & -0.25 \\
\hline $200 \mathrm{~m}$ downstream the outlet of the station (RB) & 36.72 & 37.0 & -0.28 \\
\hline At the outlet of the station (LB) & 41.71 & 42.0 & -0.29 \\
\hline At the outlet of the station (M) & 41.12 & 41.0 & +0.12 \\
\hline At the outlet of the station (RB) & 39.34 & 39.50 & -0.16 \\
\hline $100 \mathrm{~m}$ upstream the outlet of the station (LB) & 37.27 & 37.50 & -0.23 \\
\hline $100 \mathrm{~m}$ upstream the outlet of the station (M) & 36.14 & 36.0 & +0.14 \\
\hline $100 \mathrm{~m}$ upstream the outlet of the station (RB) & 38.12 & 38.50 & -0.38 \\
\hline $112 \mathrm{~m}$ downstream the inlet of the station (LB) & 36.71 & 37.0 & -0.29 \\
\hline $112 \mathrm{~m}$ downstream the inlet of the station (M) & 35.28 & 35.50 & -0.22 \\
\hline $112 \mathrm{~m}$ downstream the inlet of the station (RB) & 37.65 & 37.50 & +0.15 \\
\hline At the inlet of the station (LB) & 35.43 & 35.50 & -0.07 \\
\hline At the inlet of the station (M) & 34.53 & 35.0 & -0.47 \\
\hline At the inlet of the station (RB) & 31.14 & 31.50 & -0.36 \\
\hline $50 \mathrm{~m}$ upstream the inlet of the station (LB) & 28.35 & 28.50 & -0.15 \\
\hline $50 \mathrm{~m}$ upstream the inlet of the station (M) & 26.73 & 27.0 & -0.27 \\
\hline $50 \mathrm{~m}$ upstream the inlet of the station (RB) & 24.33 & 24.50 & -0.17 \\
\hline Inside the inlet of the station & 32.20 & 32.0 & +0.2 \\
\hline
\end{tabular}

LB: left bank, RB: right bank, M: middle of the river.

river normal temperature $\left(25^{\circ} \mathrm{C}\right)$ and this due to the hydraulic short-circuiting, where the thermally charged cooling water flows upstream and toward the inlet of the station. This occurs because the discharging and withdrawing water velocities are much higher than the river water velocity.

The CFD analysis was performed to simulate the first proposed scenario in which the outlet width was increased from $9.0 \mathrm{~m}$ to $27.0 \mathrm{~m}$. The other parameters were kept the same as the existing case, the distance between the inlet and the outlet is $412 \mathrm{~m}$ and the discharge angle is perpendicular to the river flow. Figure 8 shows the temperature distribution through the entire geometry. It is obvious that the water temperature increases at the inlet of the station and reaches $31.0^{\circ} \mathrm{C}$. This solution is ineffective, especially in the existence of high withdrawing velocity, where increasing the outlet width will reduce the discharging velocity, which in turn will enhance the chance of returning the cooling water to the power station.

The second proposed scenario was to construct a new outlet in order to increase the distance between the inlet and the outlet. Figure 9 and Figure 10 illustrate effects of the purposed construction of a new outlet at distance $612 \mathrm{~m}$ or $912 \mathrm{~m}$ downstream the inlet of the station. The other parameters were kept the same as the existing case, the new outlet has the same dimensions (9-m width and 3-m depth) and the discharge angle is perpendicular to the river flow. The water temperature at the inlet of the station reached $30^{\circ} \mathrm{C}$ and $28^{\circ} \mathrm{C}$ for distance $612 \mathrm{~m}$ and $912 \mathrm{~m}$, respectively. Consequently, this solution is also ineffective because the water temperature at the inlet still higher than the river normal temperature even after doubling the distance between the inlet and the outlet. In addition, the high withdrawing velocity plays an important role in returning the cooling water to the inlet.

The third proposed scenario was to construct a new outlet at distance $612 \mathrm{~m}$ downstream the inlet with dimensions 27-m width and 3-m depth, while the discharge angle is perpendicular to the river flow. Figure 11 shows the temperature distribution along the study area. The CFD results showed that the water temperature at the inlet is expected to be $26.5^{\circ} \mathrm{C}$ which means that constructing the outlet at a reasonable width and depth, as 


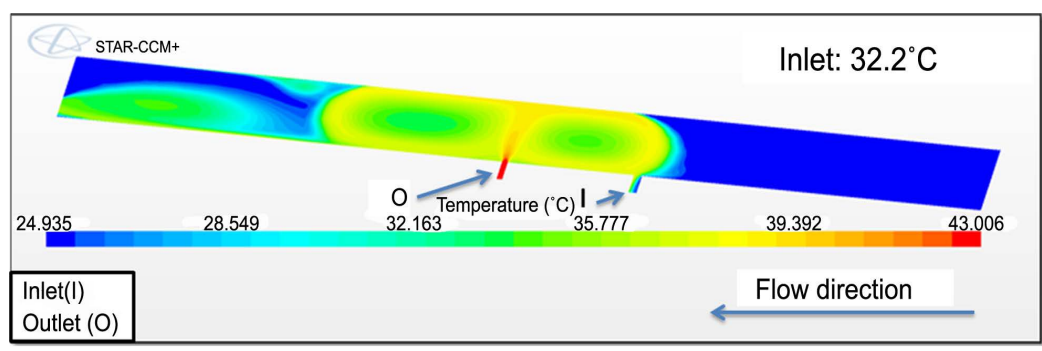

Figure 7. The temperature distribution along the study area for the current situation.

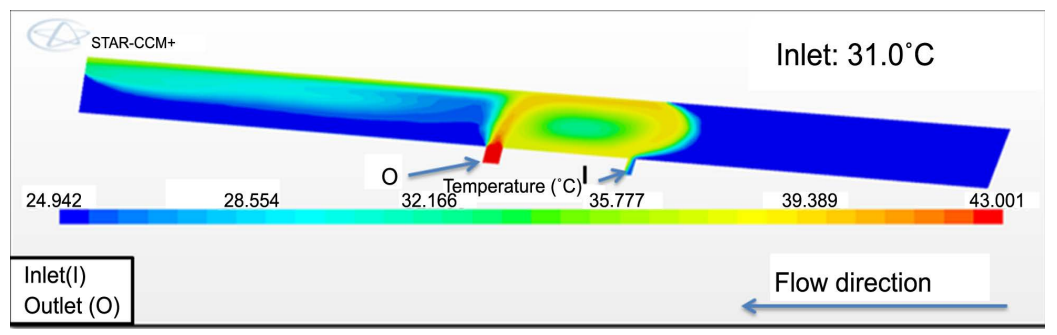

Figure 8 . The temperature distribution along the study after increasing the outlet width from $9 \mathrm{~m}$ to $27 \mathrm{~m}$.

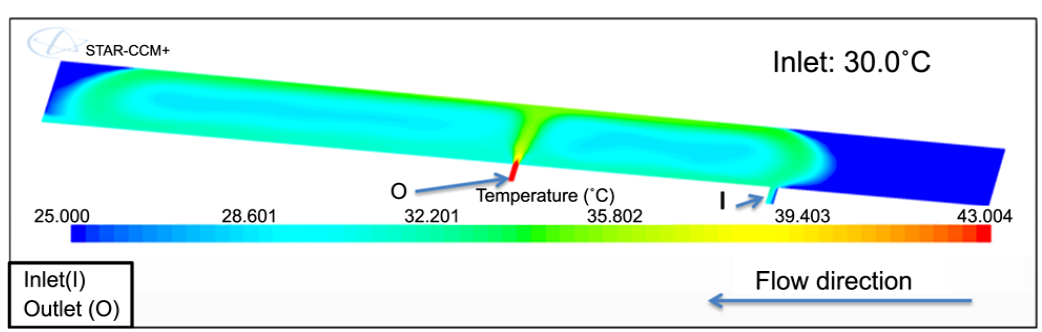

Figure 9. The temperature distribution along the study area after increasing the distance between the inlet and the outlet from $412 \mathrm{~m}$ to $612 \mathrm{~m}$.

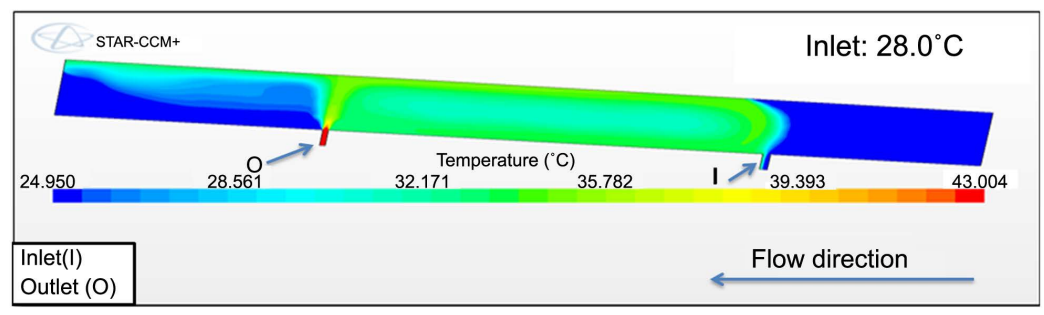

Figure 10. The temperature distribution along the study area after increasing the distance between the inlet and the outlet from $412 \mathrm{~m}$ to $912 \mathrm{~m}$.

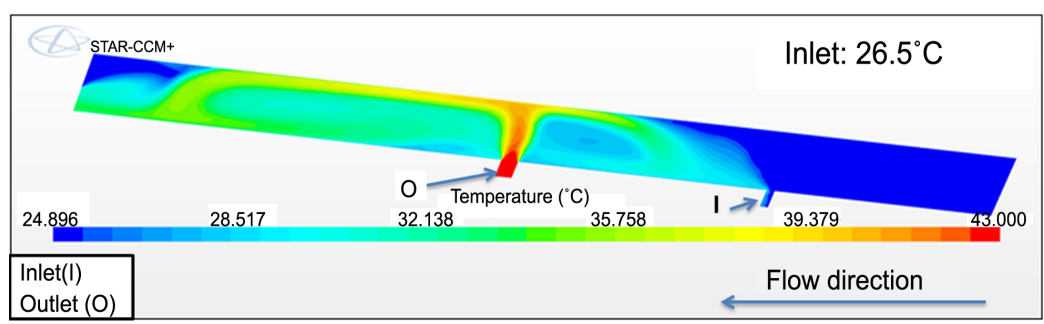

Figure 11. The temperature distribution along the study area after constructing new outlet with $27 \mathrm{~m}$ width and $3 \mathrm{~m}$ water depth and at distance $612 \mathrm{~m}$ downstream the inlet. 
well as at a reasonable distance from the inlet will significantly reduce the chances of returning the cooling water to the power station.

The forth proposed scenario was to change the discharge angle of the existing outlet. Figure 12 and Figure 13 show the situation in case of change the discharge angle from $90^{\circ}$ to $120^{\circ}$ and $135^{\circ}$. The other parameters were kept the same as the existing case, the distance between the inlet and the outlet is $412 \mathrm{~m}$ and the outlet dimensions is 9-m width and 3-m depth. The water temperature at the inlet of the station reached $29^{\circ} \mathrm{C}$ and $25^{\circ} \mathrm{C}$ for the discharge angle $120^{\circ}$ and $135^{\circ}$, respectively. It is clear that there is no noticeable change in the temperature at the inlet and it remains $25^{\circ} \mathrm{C}$ as the normal temperature of the river flow. Consequently, this solution is more effective than the other proposed solutions, especially after increasing the discharge angle to $135^{\circ}$. At angle $135^{\circ}$, the discharging water will not be influenced by the concrete wall on the other side of the river (see Figure 13); consequently, the hot water will not flow toward the inlet of the station. If the water temperature at the inlet decreases from $32^{\circ} \mathrm{C}$ to $25^{\circ} \mathrm{C}$, the discharge water temperature at the outlet should also decreases by up to 7 degrees from $43^{\circ} \mathrm{C}$ to $36^{\circ} \mathrm{C}$. This solution is also not expensive to be implemented comparing with the previous proposed solutions Because this approach could be easily applied without the need for further construction works, while the previous proposed solutions require a big budget to construct new outlet.

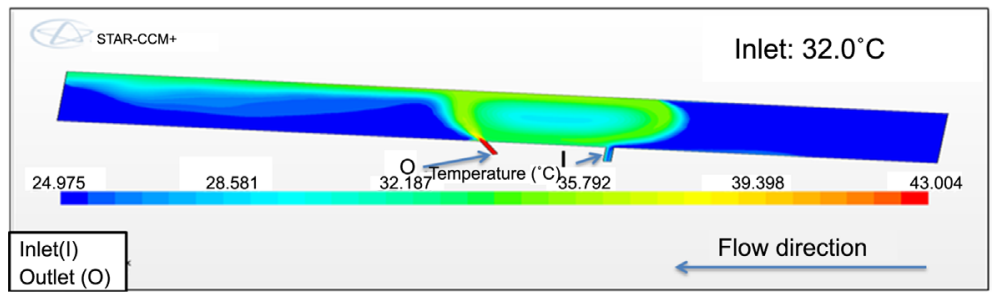

Figure 12. The temperature distribution along the study area after increasing the discharge angle from $90^{\circ}$ to $120^{\circ}$.

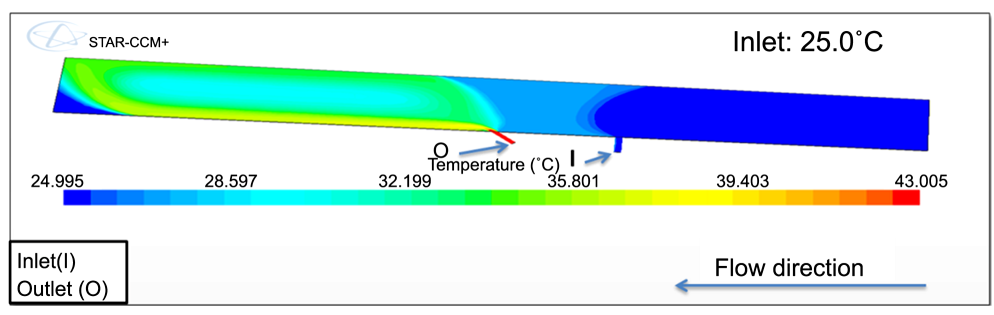

Figure 13. The temperature distribution along the study area after increasing the discharge angle from $90^{\circ}$ to $135^{\circ}$.

\section{Conclusions}

Thermal pollution can create a variety of adverse impacts on the environment and may generate tremendous stress within the aquatic ecosystem. Therefore, this effort targeted ways to reduce the effect of the thermal pollution by preventing the cooling water from being short-circuited. The case study was conducted on Kafr-Al-Batek power station. At present, the intake of the station exhibits a temperature of $32^{\circ} \mathrm{C}$ resulting from the short spatial distance between the inlet and the outlet. Furthermore, because the water velocity at the outlet $(2.0 \mathrm{~m} / \mathrm{sec})$ is much higher than the water velocity upstream of the outlet $(0.37 \mathrm{~m} / \mathrm{sec})$, the discharged water can flow nearly perpendicularly to the river where it is obstructed by an erosion protection wall. Coupled with the intake velocity $(3.0 \mathrm{~m} / \mathrm{s})$, the thermal flux is dissipated upstream and can adversely influence the cooling system [4].

Regression analysis for the actual and predicted values was performed using Microsoft Excel, and the correlation coefficients were obtained to help identify the nature of correlations between the actual and predicted values. A significant correlation coefficient value $(r \sim 0.998)$ was obtained between both data sets. The CFD results also showed that the solution of changing the discharge angle was more effective than the other proposed solutions, especially after increasing the discharge angle to $135^{\circ}$ because it would effectively prevent the cooling water from returning to the inlet of the station. Therefore, it is recommended to physically change the discharge angle from $90^{\circ}$ to $135^{\circ}$ in order to keep the water temperature at the inlet of the station the same as the ambient tem- 
perature of the river. Applying this solution should decrease the discharge water temperature at the outlet by up to 7 degrees (from $43^{\circ} \mathrm{C}$ to $36^{\circ} \mathrm{C}$ ) which may significantly reduce the effect of the thermal pollution along the Damietta branch of the Nile River in Egypt. This solution is also more cost-effective than the other proposed solutions.

\section{References}

[1] Ager, D., David, M. and Paul, P. (2008) Bay Shore Power Plant Cooling Water Intake Structure Information and I\&E Sampling Data. Environment and Aquatic Management Services, Algonquin.

[2] Nathanson, J.A. (2013) E-Study guide for: Basic Environmental Technology: Water Supply, Waste Management and Pollution Control. 9th Edition, Just The Facts I0I Textbook Key Facts, Content Technologies Inc., Bellevue.

[3] Agarwal, R.K. and Sangal, V.K. (2010) Environment and Ecology. Krishna Prakashan Media (P) Ltd., Meerut.

[4] Mostafa, M. (2014) Modeling of Pollutant Transport in the Nile Delta Egypt. Ph.D. Dissertation. University of Alabama at Birmingham, Birmingham.

[5] Nordell, B. (2003) Thermal Pollution Causes Global Warming. Global and Planetary Change, 38, 305-312. http://dx.doi.org/10.1016/S0921-8181(03)00113-9

[6] Walkuska, G. and Agnieszka, W. (2010) Influence of Discharged Heated Water on Aquatic Ecosystem Fauna. Faculty of Veterinary Medicine in Lublin, University of Life Sciences in Lublin, Lublin, Poland. http://www.pjoes.com/pdf/19.3/547-552.pdf

[7] Andrew, D.E., Lenore, S.C., Eugene, W.R. and Arnold, E.G. (2005) Standard Methods for the Examination of Water and Wastewater. 21st Edition, American Public Health Association, Washington DC.

[8] American Public Health Association (APHA) (2005) Standard Methods for the Examination of Water and Wastewater. Washington DC.

[9] Clesceri, L.S., Greenberg, A.E. and Trussell, R.R. (1989) Standard Methods for the Examination of Water and Wastewater. 17th Edition, American Public Health Association, Washington DC.

[10] Department of Defense (2011) High Performance Computing Modernization Program. Users Group Conference, Portland.

[11] Coker, A.K. (2001) Modeling of Chemical Kinetics and Reactor Design. Gulf publishing Company, Houston.

[12] Haren, S.W. (2011) Testing DNS Capability of Open FOAM and STAR-CCM+. Master Thesis, Delft University of Technology, Delft.

[13] Bertholds, A. (2013) Efficient Modeling of the Regenerative Heat Transfer in a Rotary Kiln. Project in Computational Science: Report, Uppsala University, Uppsala. 